Article

\title{
Behavioural Variability in Chicks vs. the Pattern of Behaviour in Adult Hens
}

\author{
Iwona Rozempolska-Rucińska, Kornel Kasperek ${ }^{\mathbb{D}}$, Kamil Drabik ${ }^{\mathbb{D}}$, Grzegorz Zięba ${ }^{\mathbb{D}}$ and \\ Agnieszka Ziemiańska *
}

Institute of Biological Basis of Animal Production, University of Life Sciences in Lublin, Akademicka 13, 20-950 Lublin, Poland; iwona.rucinska@up.lublin.pl (I.R.-R.); kornel.kasperek@up.lublin.pl (K.K.); kamil.drabik2@gmail.com (K.D.); grzegorz.zieba@up.lublin.pl (G.Z.)

* Correspondence: agnieszka.ziemianska@up.lublin.pl; Tel.: +48-504505885

Received: 22 December 2019; Accepted: 6 February 2020; Published: 9 February 2020

Simple Summary: Environmental requirements ensuring behavioural welfare to laying hens may vary depending on the breed. Chickens representing various breeds and reared in the same environment were found not only to differ in the level of activity, emotional arousal, and degree of curiosity, but also to prefer different enrichments of the environment, which was reflected by different levels of stress in these birds. Hence, a question was posed whether the behavioural differences observed were innate behavioural patterns typical of the breed or whether they are an effect of the modifying impact of the environment, which varies between breeds. It has been hypothesised that differences observed already in chicks of different breeds may not be associated with the modifying effect of the environment. Instead, they may be a genetically determined breed-specific behaviour. The present investigations consisted in behavioural tests and assessment of the behaviour of chicks of three laying hen breeds. The study involved 60 green-legged partridge $(\mathrm{Zk}), 60$ Polbar $(\mathrm{Pb})$, and 60 Leghorn $(\mathrm{Lg})$ chicks. The investigations have demonstrated that the birds from the analysed breeds exhibit behavioural differences already on the first days of life. The effect of the breed was evident in the case of such traits as strategy for acquisition of food resources, fearfulness/curiosity, and interest in elements of the environment. With age, chicks may exhibit changes in their emotions, e.g., more pronounced fearfulness, and environmental preferences. However, in the latter case, there is clear tendency towards breed-specific behaviours exhibited from the first days of life. The level of activity, which largely differentiates adult birds, does not discriminate between chicks.

Abstract: The aim of the study was to assess the behaviour of chicks of three different breeds of laying hens differing in the activity, emotional reactivity, and environmental preferences. Another objective was to answer the question whether the behavioural differences between adult birds would be evident already in the chick period or whether they are an effect of the further modifying impact of the environment. 60 green-legged partridge, 60 Polbar, and 60 Leghorn chicks were used in the experiments. The chicks hatched in a flock where hens were previously assessed with behavioural tests and the corticosterone levels in their feathers was determined, indicating significant differences in the temperament and stress level between the breeds. Five tests were carried out: two on competitiveness, activity, interest and fearfulness/curiosity. The experiments revealed considerable differences between the chicks. The $\mathrm{Zk}$ birds coped better with situations requiring swiftness and initiative. The $\mathrm{Pb}$ chicks were slower than Zk and Lg and did not make quick decisions. Hence, a lower number of these birds entering and leaving the test cage and staying inside was recorded. The Zk chicks exhibited a higher level of fearfulness than the other breeds. In terms of the environment enrichment elements, sand and woodchips were more attractive to the $\mathrm{Zk}$ chicks, whereas the $\mathrm{Lg}$ and $\mathrm{Pb}$ birds preferred pecking the string. No differences in the time of undertaking the analysed activities were found between the breeds. 
Keywords: behavioural test; breed of laying hens; chick; temperament

\section{Introduction}

To ensure birds' welfare, their housing environment has to be adjusted to not only biological but also behavioural needs. The following questions associated with the welfare and housing conditions provided to chickens arise: (i) Is the genotype of birds suitable for each type of environment? and (ii) is it necessary to adjust the environment (rearing practices) to the genotype? [1,2]. It appears that birds' environmental needs may vary not only between species but also between breeds [3] and individuals of the same breed [4]. Previous investigations [3,5] have demonstrated that hens from three different breeds (green-legged partridge- $\mathrm{Zk}$, Polbar- $\mathrm{Pb}$, and Leghorn $-\mathrm{Lg}$ ) kept in environments as identical as possible not only differed in the level of activity, emotional arousal, or degree of curiosity, but also preferred different enrichments of the environment, which collectively resulted in a different level of stress in the birds [5]. The Zk breed showed interest in objects that allowed scratching and searching, i.e., the birds preferred a container filled with finely shredded straw and woodchips as well as insect larvae but ignored a feed container, shelter box, or mirror. Simultaneously, the breed was assigned the lowest level of stress. The Lg chicks were mainly interested in the mirror and observation of their reflection, whereas the $\mathrm{Pb}$ chickens did not exhibit specific preferences, although they tended to be attracted to the sand contained. Both breeds had a higher level of stress than the Zk chicks. The authors reported that the living environment fulfilled the needs of the Zk breed only, but failed to satisfy the needs of the Lg hens [3,5]. The birds were kept on bedding and thus the need of the Zk chickens to scratch and search was satisfied.

Since the behavioural patterns depend on the genetic background, previous bird's experiences, environmental conditions prevailing during embryonic development, and epigenetic effects [4,6-9], a question was posed whether the differences observed in the behaviour of the three breeds $(\mathrm{Zk}, \mathrm{Lg}$, $\mathrm{Pb}$ ) were innate breed-specific behavioural patterns or whether they were "generated" by their living environment. In other words, the question was whether the rearing practice, which was not adjusted to the genetic predisposition of the breed, was the cause of the behavioural differences or whether the breed-specific differences occurred regardless of the rearing practices. An environment that prevents expression of behaviours to which the animal is motivated may evoke other variants of behaviour, often leading to behavioural problems [10]. These issues are highly important for an adequate choice of birds suitable for various rearing systems, where genetic-environmental interactions may result in problems with welfare and, consequently, productivity $[1,2,11]$.

The research hypothesis assumes that any differences in the behaviour between young chicks of different breeds cannot result from the modifying impact of the environment at such an early age.

Behavioural variability in this case is associated with innate behavioural patterns. In turn, if the differences in the behaviour between chicks of different breeds are insignificant, it can be assumed that the behaviour of adult hens is an effect of environmental factors.

The aim of the study was to assess the behaviour of chicks representing three different laying hen breeds whose adults differ in the activity, emotional reactivity, and environmental preferences. Another objective was to answer the following questions:

- Will the differences be evident already in the chick period as breed-specific traits?

- Will the chicks exhibit no behavioural differences? This would indicate that differences in behaviour visible in adult birds are not breed-specific patterns but are associated by the modifying effect of the environment. 


\section{Materials and Methods}

All procedures employed during the research were approved by the II Local Ethics Committee for Animal Testing at the University of Life Sciences in Lublin, Poland (Approval No. 69/2017 of 28 September 2017). Chicks of three breeds of laying hens were used in the experiments: 60 green-legged partridge $(\mathrm{Zk}), 60$ Polbar $(\mathrm{Pb})$, and 60 Leghorn $(\mathrm{Lg})$ birds. The chicks hatched in a flock where hens were previously assessed with behavioural tests and the corticosterone levels in their feathers was determined, indicating significant differences in the temperament and stress level between the breeds [3,5].

The native $\mathrm{Zk}$ breed with colourful plumage is often reared in organic farming systems. These hens are perfectly adapted to the conditions of extensive free-range farming. $\mathrm{Pb}$ is an autosexing hybrid that has emerged via mating of Green-legged partridge hens with Plymouth Rock cocks. The birds of this breed have dappled plumage. Lg birds with white plumage are one of the most popular breeds of laying hens in Europe. It is extremely well adapted to intensive rearing. Lg hens lay approximately 230 eggs each with a weight of $65.5 \mathrm{~g}$. The laying performance of $\mathrm{Zk}$ and $\mathrm{Pb}$ hens, which are kept in conservative non-selected flocks, is substantially lower, i.e., 160 eggs with an average weight of $45 \mathrm{~g}$. The body weight of 18 -week-old birds is $\mathrm{Pb}-1350 \mathrm{~g}, \mathrm{Zk}-120 \mathrm{~g}$, and Lg-1300g (data provided by inspection of the laying performance of the analysed flocks).

One-day-old chicks were placed in 6 pens. There were 10 individuals of each breed in each pen, i.e., 30 chicks in total. The group of birds within the pen did not change from the 1st to 23 rd day of life. The only exception was one of the pens where a Leghorn chick was replaced on the 2nd day of life due to health condition. The pens with a surface area of $100 \mathrm{~cm} \times 70 \mathrm{~cm}\left(210 \mathrm{~cm}^{2}\right.$ of free space per chick) and $60-\mathrm{cm}$ high walls were kept in an experimental room at controlled temperature $\left(22^{\circ} \mathrm{C}\right)$ and humidity $(68 \%)$. Each pen was heated with a $250 \mathrm{~W}$ infrared heater controlling the temperature of the pen floor, i.e., $31^{\circ} \mathrm{C}$ in the case of the one-day-old chicks. The temperature was gradually reduced to $23{ }^{\circ} \mathrm{C}$ on the 21 st day of life. Each pen was equipped with two round drinkers with a 20-cm diameter and two 30-cm long feeders adapted for chicks. Complete diet and water were available ad libitum. The chicks were randomly selected for the experiment from a group of 500 chicks that had hatched on the Experimental Farm of the Scientific Institute. The birds were randomly allocated in the pens. The chicks from the different breeds differ in the colour of fluff, which facilitated identification thereof during subsequent experiments. The body weight of the chicks ranged from 35 to $37 \mathrm{~g}$ and did not differ significantly between the breeds. The five tests employed in the experiment are described in detail in Table 1. Each test was recorded with a digital camera. In total, 20-h recordings of 10-min tests and 36-h recordings of 30-min tests were analysed. The tests were carried out once a day from 9:00 to 16:00, each time starting with a different pen. The tests were started at different times of the day and in different order to exclude behavioural conditioning. The next test on the same day was conducted only when the chicks from all pens exhibited chick ethogram-specific behaviours, i.e., rest, feed and water ingestion, and exploration.

The recorded indicators did not have a normal distribution; hence, the data was subjected to rank transformation. Multiple comparisons with the Bonferroni correction of the estimates of differences in the examined traits between the breeds were analysed in two-factor models, taking into account the effect of the genetic group and the age of chicks at the time of the experiment. The number of the pen where the chicks were kept was not a significant factor and was therefore not included in the analyses. The GLIMMIX procedure (SAS Institute, Cary, NC, USA) was applied. The results are presented for the chicks on the first and last days of the experiment and for the entire test period. 
Table 1. Description of the experiment and estimators of chicks' behaviour.

\begin{tabular}{|c|c|c|c|c|c|c|}
\hline Test & Course of the Experiment & $\begin{array}{c}\text { Indicator/Measurement } \\
\text { Unit }\end{array}$ & $\begin{array}{l}\text { Day of Measurement } \\
\text { (Age in Days) }\end{array}$ & Measurement & $\begin{array}{l}\text { Duration of the Test } \\
\text { (Min) }\end{array}$ & Definition \\
\hline \multirow{4}{*}{ Competitiveness I } & \multirow{4}{*}{$\begin{array}{l}\text { A cage with openwork walls and an } \\
\text { outlet allowing simultaneous } \\
\text { entry/exit of only } 1 \text { chick was placed } \\
\text { into the pen where the chicks were } \\
\text { kept. The cage was placed in the pen } \\
\text { at different times of the day. It } \\
\text { contained feed enriched with treats. }\end{array}$} & $\begin{array}{l}\text { Number of birds inside the } \\
\text { cage/birds }\end{array}$ & \multirow{4}{*}{$3,6,9,12,15,18,21$} & every $1 \mathrm{~min}$ & \multirow{4}{*}{10} & $\begin{array}{l}\text { Number of chicks of each } \\
\text { breed inside the cage and the } \\
\text { time of entry of the first chick } \\
\text { of each breed }\end{array}$ \\
\hline & & $\begin{array}{l}\text { Number of birds entering } \\
\text { the cage/ birds }\end{array}$ & & $\begin{array}{l}\text { Observation } \\
\text { throughout the test }\end{array}$ & & $\begin{array}{l}\text { Number of chicks of each } \\
\text { breed entering the cage }\end{array}$ \\
\hline & & $\begin{array}{l}\text { Number of birds leaving } \\
\text { the cage/birds }\end{array}$ & & $\begin{array}{l}\text { Observation } \\
\text { throughout the test }\end{array}$ & & $\begin{array}{l}\text { Number of chicks of each } \\
\text { breed leaving the cage }\end{array}$ \\
\hline & & $\begin{array}{l}\text { Number of birds present } \\
\text { next to the cage/ birds }\end{array}$ & & every $1 \mathrm{~min}$ & & $\begin{array}{l}\text { Number of birds of each } \\
\text { breed staying next to the cage } \\
\text { walls }\end{array}$ \\
\hline \multirow{2}{*}{ Competitiveness II } & \multirow{2}{*}{$\begin{array}{l}\text { The chicks were given a fragment of a } \\
\text { nettle leaf with the midrib, } \\
\text { which prevented them from eating } \\
\text { thereof }\end{array}$} & $\begin{array}{l}\text { Time of holding the nettle } \\
\text { leaf in the beak/seconds }\end{array}$ & \multirow{2}{*}{$4,7,10,13,16,20$} & $\begin{array}{l}\text { Observation } \\
\text { throughout the test }\end{array}$ & \multirow[t]{2}{*}{10} & $\begin{array}{l}\text { The duration of holding the } \\
\text { nettle leaf in the beak by the } \\
\text { chicks of each breed was } \\
\text { recorded }\end{array}$ \\
\hline & & $\begin{array}{l}\text { Number of pecks of the } \\
\text { nettle leaf/number }\end{array}$ & & $\begin{array}{l}\text { Observation } \\
\text { throughout the test }\end{array}$ & & $\begin{array}{l}\text { The number of pecks of the } \\
\text { leaf by each chick was } \\
\text { recorded }\end{array}$ \\
\hline Activity/birds & $\begin{array}{l}\text { The chicks were allowed to undertake } \\
\text { any activity with no interference of } \\
\text { any of the experimental factors }\end{array}$ & - & $4,7,10,13,16,20$ & every $1 \mathrm{~min}$ & 30 & $\begin{array}{l}\text { The number of active chicks } \\
\text { of each breed was recorded. } \\
\text { "Active" meant a chick } \\
\text { exhibiting any motor activity }\end{array}$ \\
\hline \multirow{3}{*}{ Interest } & $\begin{array}{l}\text { A container with sand and a container } \\
\text { with woodchips were placed in the } \\
\text { pen where the chicks were kept. Both } \\
\text { containers were placed apart from } \\
\text { each other to spot which one was } \\
\text { chosen by the chicks }\end{array}$ & Interest in woodchips/birds & \multirow{3}{*}{$4,7,10,13,16,20$} & \multirow{3}{*}{ every $1 \mathrm{~min}$} & \multirow{3}{*}{30} & $\begin{array}{c}\text { The number of birds of each } \\
\text { breed in the containers with } \\
\text { sand and woodchips was } \\
\text { recorded }\end{array}$ \\
\hline & $\begin{array}{l}\text { A cardboard square with a red spot } \\
\text { was placed on the wall of the pen }\end{array}$ & $\begin{array}{l}\text { Interest in the cardboard } \\
\text { square/birds }\end{array}$ & & & & $\begin{array}{l}\text { The number of birds of each } \\
\text { breed that approached and } \\
\text { pecked the cardboard square } \\
\text { was recorded }\end{array}$ \\
\hline & A cotton string was hung in the pen & $\begin{array}{l}\text { Interest in the cotton } \\
\text { string/birds }\end{array}$ & & & & $\begin{array}{l}\text { The number of birds of each } \\
\text { breed that approached and } \\
\text { pecked the string was } \\
\text { recorded }\end{array}$ \\
\hline
\end{tabular}


Table 1. Cont.

\begin{tabular}{|c|c|c|c|c|c|c|}
\hline Test & Course of the Experiment & $\begin{array}{c}\text { Indicator/Measurement } \\
\text { Unit }\end{array}$ & $\begin{array}{l}\text { Day of Measurement } \\
\text { (Age in Days) }\end{array}$ & Measurement & $\begin{array}{l}\text { Duration of the Test } \\
\text { (Min) }\end{array}$ & Definition \\
\hline \multirow[b]{2}{*}{ Fearfulness/curiosity } & \multirow{2}{*}{$\begin{array}{l}\text { A board }(20 \mathrm{~cm} \times 20 \mathrm{~cm}) \text { with a } \\
\text { marked centre was placed in the pen, } \\
\text { on which the observer placed his/her } \\
\text { hand. The hand did not move }\end{array}$} & Approach to the hand/birds & \multirow[b]{2}{*}{$3,6,9,12,15,18,21$} & \multirow[b]{2}{*}{ every $1 \mathrm{~min}$} & \multirow[b]{2}{*}{10} & $\begin{array}{l}\text { The number of birds of each } \\
\text { breed that stepped on the } \\
\text { board was recorded }\end{array}$ \\
\hline & & $\begin{array}{l}\text { Direct contact with the } \\
\text { hand/birds }\end{array}$ & & & & $\begin{array}{l}\text { The number of birds of each } \\
\text { breed that stepped on the } \\
\text { hand or pecked the hand was } \\
\text { recorded }\end{array}$ \\
\hline
\end{tabular}




\section{Results}

The competitiveness of the chicks was assessed by recording the number of birds from the analysed breeds staying inside the cage with feed, entering and leaving the cage at a specific time, and staying next to the cage with a clear indication of the willingness to enter the cage (Table 2).

Table 2. Mean level of analysed indicators * and significance of differences between the means in the Competitiveness I test in relation to the breed and age of chicks.

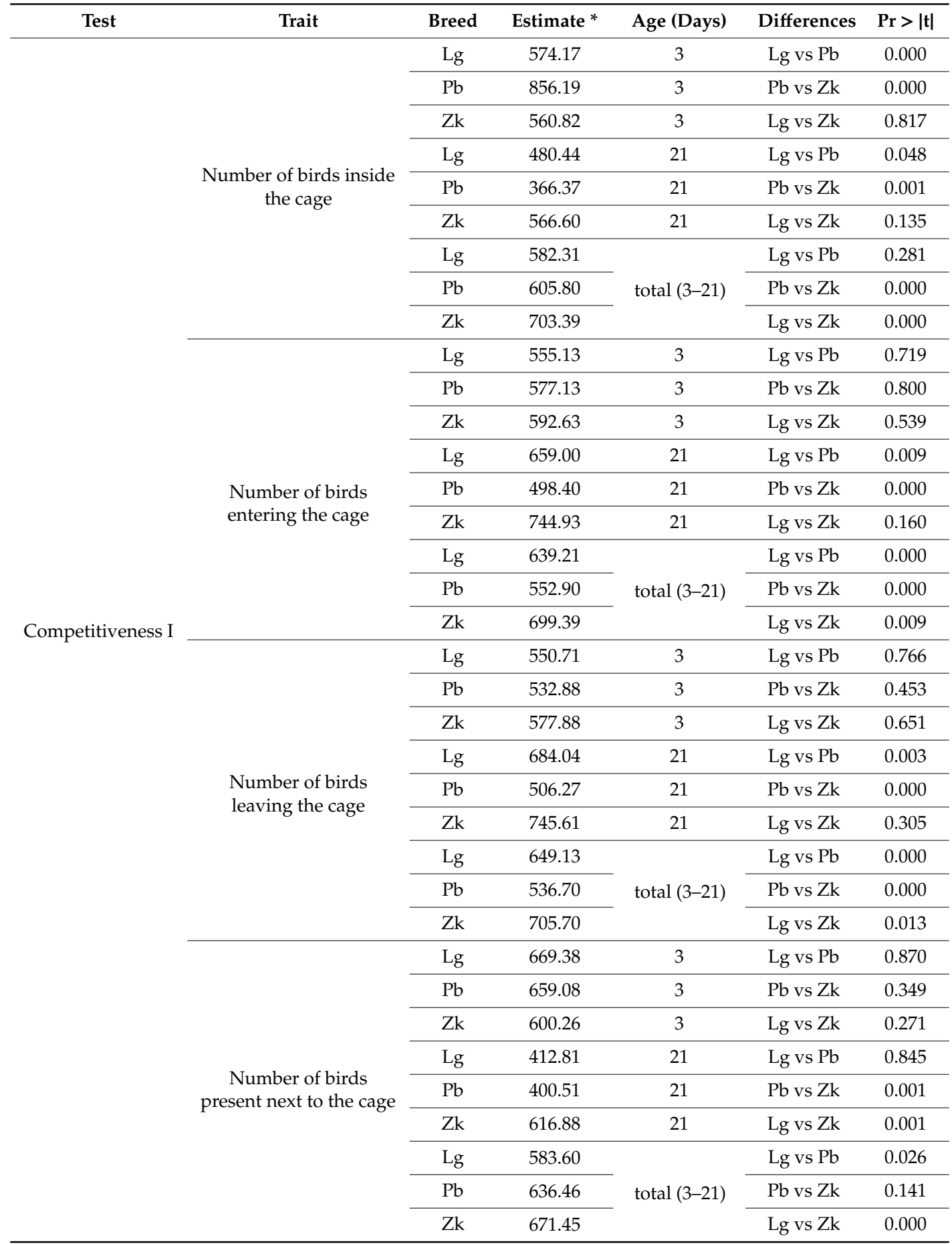

* rank-transformed means; Lg, Leghorn; Pb, Polbar; Zk, Green-legged Partridge; Pr > |t|: significance level. 
The largest group of three-day-old chicks present inside the cage was represented by the $\mathrm{Pb}$ breed. However, the lowest number of $\mathrm{Pb}$ chicks was noted inside the cage in the three -week-old group.

Noteworthy, there were no significant differences in the number of the three-day-old chicks of the respective breeds entering, leaving, and staying next to the cage. Such differences were recorded at the age of three weeks: the greatest number of chicks entering and leaving the cage represented the $\mathrm{Zk}$ and $\mathrm{Lg}$ breeds, and $\mathrm{Pb}$ chicks accounted for the lowest number.

The assessment of the numbers of birds entering and leaving the cage showed no significant differences between $\mathrm{Zk}$ and $\mathrm{Lg}$ on day 3 and day 21. In turn, in terms of the total measurements in the experimental period, the $\mathrm{Zk}$ chicks represented the biggest number in the observations of each of the traits.

In the next competitiveness test (II), the time to approach to the nettle leaf and the number of pecks were evaluated (Table 3). Zk appeared to be the most responsive breed in comparison with the other chicks. There were no significant differences between the breeds only in one case, i.e., the time of holding of the nettle in the beak did not differ between the four-day-old $\mathrm{Zk}$ and Pb chicks. The $\mathrm{Zk}$ chicks exhibited the greatest interest in the object measured by the number of pecks. The time of holding of nettle in the beak and the number of pecks did not differ between the $\mathrm{Pb}$ and $\mathrm{Lg}$ breeds, regardless of the age.

Table 3. Mean level of analysed indicators* and significance of differences between the means in the Competitiveness II test in relation to the breed and age of chicks.

\begin{tabular}{|c|c|c|c|c|c|c|}
\hline Test & Indicator & Breed & Estimate* & Age (days) & Differenc & $\operatorname{Pr}>|t|$ \\
\hline \multirow{18}{*}{ Competitiveness II } & \multirow{9}{*}{$\begin{array}{l}\text { Time of holding } \\
\text { the nettle in the } \\
\text { beak (seconds) }\end{array}$} & $\mathrm{Lg}$ & 189.89 & 4 & Lg vs $\mathrm{Pb}$ & 0.577 \\
\hline & & $\mathrm{Pb}$ & 209.55 & 4 & Lg vs Zk & 0.041 \\
\hline & & Zk & 256.53 & 4 & $\mathrm{~Pb}$ vs $\mathrm{Zk}$ & 0.066 \\
\hline & & $\operatorname{Lg}$ & 244.54 & 20 & Lg vs $\mathrm{Pb}$ & 0.498 \\
\hline & & $\mathrm{Pb}$ & 273.80 & 20 & Lg vs Zk & 0.000 \\
\hline & & $\mathrm{Zk}$ & 380.04 & 20 & $\mathrm{~Pb}$ vs $\mathrm{Zk}$ & 0.001 \\
\hline & & $\mathrm{Lg}$ & 253.11 & \multirow{3}{*}{ total $(4-20)$} & Lg vs $\mathrm{Pb}$ & 0.556 \\
\hline & & $\mathrm{Pb}$ & 234.03 & & Lg vs Zk & 0.001 \\
\hline & & $\mathrm{Zk}$ & 322.43 & & $\mathrm{~Pb}$ vs $\mathrm{Zk}$ & 0.038 \\
\hline & \multirow{9}{*}{ Number of pecks } & $\mathrm{Lg}$ & 341.67 & 4 & Lg vs $\mathrm{Pb}$ & 0.576 \\
\hline & & $\mathrm{Pb}$ & 358.05 & 4 & Lg vs Zk & 0.000 \\
\hline & & Zk & 456.06 & 4 & $\mathrm{~Pb}$ vs $\mathrm{Zk}$ & 0.001 \\
\hline & & $\mathrm{Lg}$ & 182.00 & 20 & Lg vs $\mathrm{Pb}$ & 0.186 \\
\hline & & $\mathrm{Pb}$ & 222.22 & 20 & Lg vs Zk & 0.000 \\
\hline & & Zk & 363.85 & 20 & $\mathrm{~Pb}$ vs $\mathrm{Zk}$ & 0.000 \\
\hline & & $\mathrm{Lg}$ & 257.90 & \multirow{3}{*}{ total $(4-20)$} & Lg vs $\mathrm{Pb}$ & 0.683 \\
\hline & & $\mathrm{Pb}$ & 265.67 & & Lg vs Zk & 0.000 \\
\hline & & Zk & 386.93 & & $\mathrm{~Pb}$ vs $\mathrm{Zk}$ & 0.000 \\
\hline
\end{tabular}

* rank-transformed means; Lg: Leghorn; Pb: Polbar; Zk: Green-legged Partridge; $\operatorname{Pr}>|\mathrm{t}|$ : significance level.

Summing up the competitiveness test, the $\mathrm{Zk}$ breed scored the highest results in most of the tests. The results changed with the age of the chicks and between the indicators analysed.

Another analysed trait was activity (Table 4). 
Table 4. Mean level of analysed indicators* and significance of differences between the means in the Activity test in relation to the breed and age of chicks.

\begin{tabular}{|c|c|c|c|c|c|}
\hline Test & Breed & Estimate* $^{*}$ & Age (days) & Differences & $\operatorname{Pr}>|t|$ \\
\hline \multirow{9}{*}{ Activity (no.) } & $\mathrm{Lg}$ & 463.24 & 4 & Lg vs $\mathrm{Pb}$ & 0.999 \\
\hline & $\mathrm{Pb}$ & 463.32 & 4 & Lg vs Zk & 0.113 \\
\hline & $\mathrm{Zk}$ & 533.07 & 4 & $\mathrm{~Pb}$ vs $\mathrm{Zk}$ & 0.113 \\
\hline & $\mathrm{Lg}$ & 415.86 & 20 & Lg vs $\mathrm{Pb}$ & 0.823 \\
\hline & $\mathrm{Pb}$ & 425.71 & 20 & Lg vs Zk & 0.332 \\
\hline & $\mathrm{Zk}$ & 458.56 & 20 & $\mathrm{~Pb}$ vs $\mathrm{Zk}$ & 0.455 \\
\hline & $\mathrm{Lg}$ & 532.81 & \multirow{3}{*}{ total $(4-20)$} & Lg vs $\mathrm{Pb}$ & 0.550 \\
\hline & $\mathrm{Pb}$ & 519.64 & & Lg vs Zk & 0.100 \\
\hline & $\mathrm{Zk}$ & 569.04 & & $\mathrm{~Pb}$ vs $\mathrm{Zk}$ & 0.025 \\
\hline
\end{tabular}

* rank-transformed means; Lg: Leghorn; Pb: Polbar; Zk: Green-legged Partridge; Pr > |t|: significance level; no: number.

The chicks did not differ significantly in the level of activity throughout the experimental period. Additionally, differences in chicks' preferences for environmental elements were estimated in the tests (Table 5).

The sand and woodchips turned out to be especially attractive to the Zk chicks. The 4-day-old Zk chicks chose the container with sand more often than $\mathrm{Pb}$ and $\mathrm{Lg}$, whereas differences in the interest in the woodchips were observed in three-week-old chicks. There were no differences between the number of $\mathrm{Lg}$ and $\mathrm{Pb}$ showing interest in these objects, irrespective of their age. In contrast to $\mathrm{Zk}$, the $\mathrm{Lg}$ and $\mathrm{Pb}$ birds were interested in the string. The Lg chicks showed interest in this object mainly in early life. There were no differences between the breeds in the older chicks.

Another trait examined in the experiment was fearfulness/curiosity (Table 6). Significant differences between the breeds were noted in the tests. The Zk chicks were characterised by a substantially higher level of fearfulness than $\mathrm{Pb}$ and $\mathrm{Lg}$. This was already evident on the first days of life and, despite the continuous positive contact with humans (feeding, treats), this trend did not change until the end of the experiment. On the first days of life, there were no differences in fearfulness between $\mathrm{Pb}$ and $\mathrm{Lg}$. However, the older Lg chicks tended to avoid stimuli and the number of birds approaching the hand was significantly lower than in the case of $\mathrm{Pb}$.

The analysis of the "direct contact with the hand" parameter demonstrated that the level of fearfulness changed with age. In the group of the three-day-old chicks, there were no significant differences, or they were on the border of significance (Lg-Zk), whereas highly significant differences in the level of fearfulness/curiosity were noted in the three-week-old chicks. Similarly, in the "approach to the hand" test, the highest level of avoidance of contact was noted in the Zk breed. The Pb breed exhibited the lowest level of fearfulness. During the test, the chicks would fall asleep in the palm of the hand and these were not sporadic cases.

There were no differences in the time of undertaking individual activities between the breeds (Table 7). 
Table 5. Mean level of analysed indicators* and significance of differences between the means in the Interest test in relation to the breed and age of chicks.

\begin{tabular}{|c|c|c|c|c|c|c|}
\hline Test & Object (Measurement) & Breed & Estimate * & Age (Days) & Differences & $\operatorname{Pr}>|t|$ \\
\hline \multirow{36}{*}{ Interest } & & $\mathrm{Lg}$ & 453.19 & 4 & Lg vs $\mathrm{Pb}$ & 0.361 \\
\hline & & $\mathrm{Pb}$ & 413.13 & 4 & Lg vs Zk & 0.031 \\
\hline & & $\mathrm{Zk}$ & 548.07 & 4 & $\mathrm{~Pb}$ vs $\mathrm{Zk}$ & 0.002 \\
\hline & & $\mathrm{Lg}$ & 557.31 & 20 & Lg vs $\mathrm{Pb}$ & 0.064 \\
\hline & Sand (no.) & $\mathrm{Pb}$ & 476.05 & 20 & Lg vs Zk & 0.074 \\
\hline & & $\mathrm{Zk}$ & 478.89 & 20 & $\mathrm{~Pb}$ vs $\mathrm{Zk}$ & 0.948 \\
\hline & & $\mathrm{Lg}$ & 539.02 & \multirow{3}{*}{ total $(4-20)$} & Lg vs $\mathrm{Pb}$ & 0.433 \\
\hline & & $\mathrm{Pb}$ & 521.79 & & Lg vs Zk & 0.324 \\
\hline & & Zk & 560.69 & & $\mathrm{~Pb}$ vs $\mathrm{Zk}$ & 0.077 \\
\hline & \multirow{9}{*}{ Woodchips (no.) } & $\mathrm{Lg}$ & 353.34 & 4 & Lg vs $\mathrm{Pb}$ & 0.240 \\
\hline & & $\mathrm{Pb}$ & 401.27 & 4 & Lg vs Zk & 0.167 \\
\hline & & Zk & 409.72 & 4 & $\mathrm{~Pb}$ vs $\mathrm{Zk}$ & 0.836 \\
\hline & & Lg & 506.13 & 20 & Lg vs $\mathrm{Pb}$ & 0.559 \\
\hline & & $\mathrm{Pb}$ & 482.34 & 20 & Lg vs Zk & 0.001 \\
\hline & & Zk & 641.58 & 20 & $\mathrm{~Pb}$ vs $\mathrm{Zk}$ & 0.000 \\
\hline & & $\mathrm{Lg}$ & 521.23 & \multirow{3}{*}{ total $(4-20)$} & Lg vs $\mathrm{Pb}$ & 0.925 \\
\hline & & $\mathrm{Pb}$ & 523.14 & & Lg vs Zk & 0.006 \\
\hline & & $\mathrm{Zk}$ & 577.12 & & $\mathrm{~Pb}$ vs $\mathrm{Zk}$ & 0.008 \\
\hline & \multirow{9}{*}{ Cardboard square (no.) } & $\mathrm{Lg}$ & 29.50 & 4 & Lg vs $\mathrm{Pb}$ & 0.249 \\
\hline & & $\mathrm{Pb}$ & 46.66 & 4 & Lg vs Zk & 0.779 \\
\hline & & $\mathrm{Zk}$ & 34.17 & 4 & $\mathrm{~Pb}$ vs $\mathrm{Zk}$ & 0.168 \\
\hline & & $\mathrm{Lg}$ & 29.50 & 20 & Lg vs $\mathrm{Pb}$ & 0.811 \\
\hline & & $\mathrm{Pb}$ & 34.54 & 20 & Lg vs Zk & 0.476 \\
\hline & & Zk & 44.83 & 20 & $\mathrm{~Pb}$ vs $\mathrm{Zk}$ & 0.239 \\
\hline & & $\mathrm{Lg}$ & 46.67 & \multirow{3}{*}{ total $(4-20)$} & Lg vs $\mathrm{Pb}$ & 0.394 \\
\hline & & $\mathrm{Pb}$ & 37.11 & & Lg vs Zk & 0.591 \\
\hline & & Zk & 40.22 & & $\mathrm{~Pb}$ vs $\mathrm{Zk}$ & 0.612 \\
\hline & \multirow{9}{*}{ String (no.) } & Lg & 395.49 & 4 & Lg vs $\mathrm{Pb}$ & 0.023 \\
\hline & & $\mathrm{Pb}$ & 322.10 & 4 & Lg vs Zk & 0.000 \\
\hline & & $\mathrm{Zk}$ & 264.49 & 4 & $\mathrm{~Pb}$ vs $\mathrm{Zk}$ & 0.032 \\
\hline & & Lg & 315.05 & 20 & Lg vs $\mathrm{Pb}$ & 0.942 \\
\hline & & $\mathrm{Pb}$ & 317.42 & 20 & Lg vs Zk & 0.741 \\
\hline & & $\mathrm{Zk}$ & 326.36 & 20 & $\mathrm{~Pb}$ vs $\mathrm{Zk}$ & 0.709 \\
\hline & & $\mathrm{Lg}$ & 360.10 & \multirow{3}{*}{ total $(4-20)$} & Lg vs $\mathrm{Pb}$ & 0.146 \\
\hline & & $\mathrm{Pb}$ & 333.56 & & Lg vs Zk & 0.015 \\
\hline & & $\mathrm{Zk}$ & 313.21 & & $\mathrm{~Pb}$ vs $\mathrm{Zk}$ & 0.161 \\
\hline
\end{tabular}

${ }^{*}$ rank-transformed means; Lg: Leghorn; Pb: Polbar; Zk: Green-legged Partridge; Pr > |t|- significance level; no.: number. 
Table 6. Mean level of analysed indicators* and significance of differences between the means in the Fearfulness/curiosity test in relation to the breed and age of chicks.

\begin{tabular}{|c|c|c|c|c|c|c|}
\hline Test & Indicator & Breed & Estimate $^{*}$ & Age (Days) & Differences & $\operatorname{Pr}>|t|$ \\
\hline \multirow{18}{*}{ Fearfulness/curiosity } & \multirow{9}{*}{ Approach to the hand (no.) } & $\mathrm{Lg}$ & 382.72 & 3 & Lg vs $\mathrm{Pb}$ & 0.383 \\
\hline & & $\mathrm{Pb}$ & 345.53 & 3 & Lg vs Zk & 0.002 \\
\hline & & $\mathrm{Zk}$ & 250.89 & 3 & $\mathrm{~Pb}$ vs $\mathrm{Zk}$ & 0.027 \\
\hline & & $\mathrm{Lg}$ & 571.52 & 21 & Lg vs $\mathrm{Pb}$ & 0.005 \\
\hline & & $\mathrm{Pb}$ & 692.58 & 21 & Lg vs Zk & 0.000 \\
\hline & & $\mathrm{Zk}$ & 390.87 & 21 & $\mathrm{~Pb}$ vs $\mathrm{Zk}$ & 0.000 \\
\hline & & $\operatorname{Lg}$ & 502.67 & \multirow{3}{*}{ total (3-21) } & Lg vs $\mathrm{Pb}$ & 0.000 \\
\hline & & $\mathrm{Pb}$ & 563.65 & & Lg vs Zk & 0.000 \\
\hline & & $\mathrm{Zk}$ & 343.68 & & $\mathrm{~Pb}$ vs $\mathrm{Zk}$ & 0.000 \\
\hline & \multirow{9}{*}{$\begin{array}{l}\text { Direct contact with the hand } \\
\text { (no.) }\end{array}$} & $\operatorname{Lg}$ & 413.35 & 3 & Lg vs $\mathrm{Pb}$ & 0.280 \\
\hline & & $\mathrm{Pb}$ & 369.73 & 3 & Lg vs Zk & 0.045 \\
\hline & & $\mathrm{Zk}$ & 332.42 & 3 & $\mathrm{~Pb}$ vs $\mathrm{Zk}$ & 0.356 \\
\hline & & Lg & 556.85 & 21 & Lg vs $\mathrm{Pb}$ & 0.000 \\
\hline & & $\mathrm{Pb}$ & 717.54 & 21 & Lg vs Zk & 0.000 \\
\hline & & $\mathrm{Zk}$ & 407.23 & 21 & $\mathrm{~Pb}$ vs $\mathrm{Zk}$ & 0.000 \\
\hline & & $\mathrm{Lg}$ & 478.52 & \multirow{3}{*}{ total (3-21) } & Lg vs $\mathrm{Pb}$ & 0.000 \\
\hline & & $\mathrm{Pb}$ & 564.11 & & Lg vs Zk & 0.000 \\
\hline & & Zk & 367.37 & & $\mathrm{~Pb}$ vs $\mathrm{Zk}$ & 0.000 \\
\hline
\end{tabular}

* rank-transformed means; Lg: Leghorn; Pb: Polbar; Zk: Green-legged Partridge; Pr > |t|: significance level; no.: number.

Table 7. Mean time of undertaking activity * and significance of differences between the means in relation to the breed and age of chicks.

\begin{tabular}{|c|c|c|c|c|c|}
\hline Measurement & Breed & Estimate * & Age (Days) & Differences & $\operatorname{Pr}>|t|$ \\
\hline \multirow{9}{*}{$\begin{array}{c}\text { Time before entering the } \\
\text { cage (seconds) }\end{array}$} & $\mathrm{Lg}$ & 98.33 & 3 & Lg vs $\mathrm{Pb}$ & 0.239 \\
\hline & $\mathrm{Pb}$ & 79.42 & 3 & Lg vs Zk & 0.704 \\
\hline & $\mathrm{Zk}$ & 92.25 & 3 & $\mathrm{~Pb}$ vs $\mathrm{Zk}$ & 0.423 \\
\hline & $\mathrm{Lg}$ & 38.58 & 21 & Lg vs $\mathrm{Pb}$ & 0.316 \\
\hline & $\mathrm{Pb}$ & 54.67 & 21 & Lg vs Zk & 0.992 \\
\hline & Zk & 38.42 & 21 & $\mathrm{~Pb}$ vs $\mathrm{Zk}$ & 0.311 \\
\hline & $\mathrm{Lg}$ & 59.27 & \multirow{3}{*}{ total $(3-21)$} & Lg vs $\mathrm{Pb}$ & 0.081 \\
\hline & $\mathrm{Pb}$ & 69.89 & & Lg vs Zk & 0.733 \\
\hline & $\mathrm{Zk}$ & 61.33 & & $\mathrm{~Pb}$ vs $\mathrm{Zk}$ & 0.159 \\
\hline \multirow{9}{*}{$\begin{array}{l}\text { Time before entering the } \\
\text { sand container (seconds) }\end{array}$} & $\mathrm{Lg}$ & 47.92 & 4 & Lg vs $\mathrm{Pb}$ & 0.955 \\
\hline & $\mathrm{Pb}$ & 47.25 & 4 & Lg vs Zk & 0.295 \\
\hline & $\mathrm{Zk}$ & 35.50 & 4 & $\mathrm{~Pb}$ vs $\mathrm{Zk}$ & 0.321 \\
\hline & Lg & 23.08 & 20 & Lg vs $\mathrm{Pb}$ & 0.949 \\
\hline & $\mathrm{Pb}$ & 23.83 & 20 & Lg vs Zk & 0.877 \\
\hline & $\mathrm{Zk}$ & 21.25 & 20 & $\mathrm{~Pb}$ vs $\mathrm{Zk}$ & 0.827 \\
\hline & $\mathrm{Lg}$ & 36.88 & \multirow{3}{*}{ total (3-21) } & Lg vs $\mathrm{Pb}$ & 0.700 \\
\hline & $\mathrm{Pb}$ & 39.15 & & Lg vs Zk & 0.565 \\
\hline & $\mathrm{Zk}$ & 33.48 & & $\mathrm{~Pb}$ vs $\mathrm{Zk}$ & 0.339 \\
\hline
\end{tabular}


Table 7. Cont

\begin{tabular}{|c|c|c|c|c|c|}
\hline Measurement & Breed & Estimate * & Age (Days) & Differences & $\operatorname{Pr}>|t|$ \\
\hline \multirow{9}{*}{$\begin{array}{l}\text { Time before entering the } \\
\text { woodchip container } \\
\text { (seconds) }\end{array}$} & $\operatorname{Lg}$ & 58.17 & 4 & Lg vs $\mathrm{Pb}$ & 0.486 \\
\hline & $\mathrm{Pb}$ & 50.92 & 4 & Lg vs Zk & 0.538 \\
\hline & $\mathrm{Zk}$ & 51.75 & 4 & $\mathrm{~Pb}$ vs $\mathrm{Zk}$ & 0.936 \\
\hline & $\mathrm{Lg}$ & 20.42 & 20 & Lg vs $\mathrm{Pb}$ & 0.433 \\
\hline & $\mathrm{Pb}$ & 28.58 & 20 & Lg vs Zk & 0.974 \\
\hline & $\mathrm{Zk}$ & 20.08 & 20 & $\mathrm{~Pb}$ vs $\mathrm{Zk}$ & 0.415 \\
\hline & $\mathrm{Lg}$ & 35.71 & \multirow{3}{*}{ total $(3-21)$} & Lg vs $\mathrm{Pb}$ & 0.683 \\
\hline & $\mathrm{Pb}$ & 37.83 & & Lg vs Zk & 0.962 \\
\hline & $\mathrm{Zk}$ & 35.96 & & $\mathrm{~Pb}$ vs $\mathrm{Zk}$ & 0.718 \\
\hline \multirow{9}{*}{$\begin{array}{l}\text { Time before approach to the } \\
\text { hand (seconds) }\end{array}$} & Lg & 82.17 & 3 & Lg vs $\mathrm{Pb}$ & 0.714 \\
\hline & $\mathrm{Pb}$ & 76.25 & 3 & Lg vs Zk & 0.861 \\
\hline & $\mathrm{Zk}$ & 85.00 & 3 & $\mathrm{~Pb}$ vs $\mathrm{Zk}$ & 0.588 \\
\hline & Lg & 27.83 & 21 & Lg vs $\mathrm{Pb}$ & 0.159 \\
\hline & $\mathrm{Pb}$ & 50.67 & 21 & Lg vs Zk & 0.653 \\
\hline & $\mathrm{Zk}$ & 35.08 & 21 & $\mathrm{~Pb}$ vs $\mathrm{Zk}$ & 0.335 \\
\hline & $\operatorname{Lg}$ & 53.28 & \multirow{3}{*}{ total (3-21) } & Lg vs $\mathrm{Pb}$ & 0.868 \\
\hline & $\mathrm{Pb}$ & 54.38 & & Lg vs Zk & 0.697 \\
\hline & $\mathrm{Zk}$ & 55.85 & & $\mathrm{~Pb}$ vs $\mathrm{Zk}$ & 0.823 \\
\hline
\end{tabular}

* rank-transformed means; Lg: Leghorn; Pb: Polbar; Zk: Green-legged Partridge; $\operatorname{Pr}>|\mathrm{t}|$ : significance level.

\section{Discussion}

As demonstrated in many studies, the level of additive variability is so high that selection for modification of chicken's temperament may bring positive effects $[6,7,12]$. Currently, behavioural selection is mainly targeted at reduction of aggression and pterophagy [13,14]. Therefore, investigations mainly focus on adjustment of birds' temperament to the environment. However, as indicated by the present study and previous investigations conducted by the authors [3,5], there is another aspect, i.e., the environment is not universal for individual genotypes and determines hens' behaviour in various ways.

The analysis of competitiveness test I showed the highest number of Zk chicks staying inside as well as entering and leaving the cage, in comparison with the other two breeds. This test shows not only the level of competitiveness but also the strategy of behaviour, i.e., the chicks entered and stayed in the cage or left the cage to return instantly. The Zk chicks exhibited better performance in situations requiring swiftness and initiative. The $\mathrm{Pb}$ birds were slower than the $\mathrm{Zk}$ and $\mathrm{Lg}$ chicks and did not make decisions as readily, hence their lower number staying inside the cage as well as entering and leaving the cage. These differences were mainly evident in the older chicks (day 21). The Zk chicks turned out to be fast and active and definitely outcompeted the other breeds in both competitiveness tests (I and II). Importantly, Zk chicks come from parents with a lower corticosterone level in the feathers, in comparison with the $\mathrm{Lg}$ and $\mathrm{Pb}$ breeds [5]. Chicks' behaviour is modified already at the stage of embryonic development through transfer of hormones between the hen and the egg and the formation of the HPA axis involved in responses to stimuli [15-17]. As demonstrated in various studies, chicks with lower competitiveness and increased fearfulness hatch from eggs laid by hens with higher plasma corticosterone levels [8,18,19].

The competitiveness tests (I and II) demonstrated significant differences between the breeds depending on the age of the chicks. However, this was not a linear relationship, as competitiveness did 
not increase or decrease with age. Due to the limited volume of the paper, the tables show the results of tests conducted in several-day-old and several-week-old chicks (at the beginning and end of the experiment). Throughout the entire period, the differences between the competitiveness results varied and one breed had higher results at one time point but lower at another. For instance, there were no differences between the numbers of $\mathrm{Zk}$ and $\mathrm{Lg}$ chicks staying inside, entering, and leaving the cage on days 3 and 21, but such differences were found in the entire experimental period. This is highly important for inference of the competitiveness of the breeds. Although the Zk breed seemed to exhibit the highest level of competitiveness, as it outcompeted the other breeds in both competitiveness tests (I and II), we believe that this temperament trait is mainly associated with motivation. Importantly, the present competitiveness tests were based on access to feed (treats available in the cage, nettle leaves), and the intention to reach the goal is associated with motivation. Therefore, such tests mainly assess animal's motivations to take specific actions. Motivation and related emotions are the driving force in undertaking activity $[20,21]$. Noteworthy, Zk is a primitive breed specialised in search for food. These birds are eagerly kept on organic farms, as they are largely self-sufficient in satisfy their nutritional needs [22], and food search is undoubtedly their strong motivation.

A characteristic trait in this breed is the behaviour strategy, i.e., the prompt reaction and decision making, which combined with appropriate motivation allowed the Zk chicks to outcompete the other breeds. A breed-specific behaviour strategy can be assumed, but the level of breed competitiveness cannot be clearly determined, as this trait is significantly modified by animal's motivation. In our opinion, the results of the competitiveness tests were determined by the combination of a specific chick behaviour strategy and motivation.

The analysis of the activity (Table 4) of the chicks revealed quite surprising results, in comparison with our previous investigations of adult birds [3]. The study conducted by Kozak et al. [3] showed significantly higher activity of adult $\mathrm{Lg}$ birds than $\mathrm{Zk}$ and $\mathrm{Pb}$. Within the same time, $\mathrm{Lg}$ chickens examined twice as many objects and crossed a significantly larger number of squares in the open field test $[3,5]$. The tests applied to the chicks did not demonstrate differences in the activity between the breeds. Therefore, the increased activity of adult Lg chickens may be a result of environmental-induced behavioural modifications. Investigations conducted by Branciari et al [23] clearly showed a change in birds' behaviour (Lg) depending on the rearing system. As demonstrated by Kozak et al. [3,5], the behavioural needs of Lg chickens may not be fulfilled in the traditional rearing system, which may result in the "evolution" of a different behavioural system that will somehow compensate for animals' needs [24]. Access to an enriched environment at a young age exerts a positive effect on the development of brain and behaviour in adult animals [25]. In contrast, the impossibility to fulfil species/breed-specific behavioural needs leads to inappropriate development of dendrites in the brain, which results in excessive activity and excitability [21,25]. The theory of improper development of dendrites in the Lg breed should certainly be thoroughly verified; nevertheless, it has been established that these birds cannot satisfy one of their needs, i.e., curiosity, in farm conditions [3,5].

Many studies associate the excessive reactivity and fearfulness of the Lg breed with its white plumage [26,27]. The investigations conducted by Fraisse and Cockrem [28] confirmed this correlation also at the hormonal level, i.e., they showed higher concentrations of corticosterone in birds with white than brown plumage. However, the present analyses do not suggest that the excessive activity of adult $\mathrm{Lg}$ birds is characteristic for the breed. The chicks of the three tested breeds did not differ in the type or time of undertaking the activities observed (Table 7). This confirms that the excessive activity of adult Lg hens may be a result of modifying environmental effects.

An important task in the present study was to determine whether the chicks, likewise adult birds, would exhibit differences in environmental preferences. The sand and woodchips were especially attractive to the $\mathrm{Zk}$ chicks. This confirms the characteristic element in the behaviour of the breed, i.e., the need for scratching and searching. The $\mathrm{Zk}$ breed is popular on family farms and on organic farms, where birds have large areas at their disposal and cope well with searching for food. This behaviour is motivated by a strong instinct. The four-day-old Zk chicks chose the sand container more often than 
the $\mathrm{Pb}$ and $\mathrm{Lg}$ birds, while three-week-old chicks exhibited greater interest in the woodchips. With its structure, the latter material is better for scratching and searching than sand; therefore, the older Zk chicks probably preferred the woodchips. There were no differences between the number of $\mathrm{Lg}$ and $\mathrm{Pb}$ showing interest in these objects, regardless of their age. These breeds, unlike Zk, showed interest in the string. More Lg birds were interested in this object, but only in the early stages of life. There were no differences between the breeds in the older chicks. This may be related to the fact that the chicks "became bored" with the object.

The present study also confirms that fearfulness is one of the temperament traits differentiating the breeds from the first days of life (Table 6). This trait in animals is characterised by a high inheritance rate, which has also been confirmed in laying hens $[6,7]$. The study has shown that fearfulness changes over time, exhibiting a downward trend in older chicks, which may be associated with habituation to a given stimulus. The neuroendocrine system develops since the moment of hatching; with age, the activity of the HPA axis decreases, which is accompanied by a decline in the expression of the behavioural response to stress [29].

The trends observed in the individual breeds of chicks are visible in adult birds (authors' observations during the daily care of the birds). The Zk chicks were characterized by the highest level of fearfulness. As indicated by the daily observations on the farm, adult Zk birds have a tendency to avoid humans, and closer contact sometimes results in aggression, mainly in male individuals (authors' observations). This phenomenon may be associated with the origin of the breed. Zk is a primitive breed with many characteristics of its wild ancestors [22,30]. In comparison with commercial breeds, a distinctive trait of primitive breeds is the clear and more complex stress response [31] with a faster return to homeostasis [32]. This type of behavioural response allows e.g., effective avoidance of predators in the free-range by farmed primitive breeds and those living in a similar environment as their wild ancestors.

Analysis of the level of fearfulness in chicks should consider the fact that the $\mathrm{Lg}$ chicks exhibited an intermediate level of this trait between $\mathrm{Zk}$ and $\mathrm{Pb}$. The three-day-old $\mathrm{Lg}$ chicks were characterised by similar fearfulness to $\mathrm{Pb}$. However, already on day 21, they showed a significantly higher fearfulness degree, which can also be observed in adult farmed birds (own observations). Adult Lg chickens are extremely shy and reactive birds.

\section{Conclusions}

To sum up the present investigations, it can be concluded that birds of different breeds exhibit behavioural differences from the first days of life. The effect of the breed was evident in such features as the strategy for acquisition of food resources, fearfulness/curiosity, and interest in elements of the environment. In the case of environmental preferences, there is a clear tendency to show behaviours characteristic for adult birds from the first days of life. An example of such behaviour in the case of the Zk breed is the need to scratch and search. The level of activity significantly differentiating adult birds does not differentiate chicks. It is important to verify environmental factors that induce the high degree of excitability and activity in adult Lg chickens in subsequent studies. At this stage of research, it can be suggested that inadequate adjustment of the environment to the Lg breed, which exhibits, e.g., high curiosity, can change birds' behaviour, resulting in the hyperactivity of adults.

Author Contributions: Conceptualization, I.R.-R.; methodology, K.K. and A.Z.; software, G.Z.; validation, G.Z., and I.R.-R.; formal analysis, I.R.-R.; investigation, K.D.; resources, K.K.; data curation, K.K. and A.Z.; writing-original draft preparation, I.R.-R., K.D. and K.K.; writing-review and editing, A.Z.; visualization, K.D.; supervision, G.Z.; project administration, I.R.-R.; funding acquisition, G.Z. All authors have read and agree to the published version of the manuscript.

Funding: This research received no external funding.

Conflicts of Interest: The authors declare no conflict of interest. 


\section{References}

1. Phocas, F.; Belloc, C.; Bidanel, J.; Delaby, L.; Dourmad, J.Y.; Dumont, B.; Ezanno, P.; Fortun-Lamothe, L.; Foucras, G.; Frappat, B.; et al. Towards the agroecological management of ruminants, pigs and poultry through the development of sustainable breeding programmes: I-selection goals and criteria. Animal 2016a, 10, 1749-1759. [CrossRef] [PubMed]

2. Phocas, F.; Belloc, C.; Bidanel, J.; Delaby, L.; Dourmad, J.Y.; Dumont, B.; Ezanno, P.; Fortun-Lamothe, L.; Foucras, G.; Frappat, B.; et al. Towards the agroecological management of ruminants, pigs and poultry through the development of sustainable breeding programmes. II. Breeding strategies. Animal 2016b, 10, 1760-1769. [CrossRef] [PubMed]

3. Kozak, A.; Kasperek, K.; Zięba, G.; Rozempolska-Rucińska, I. Variability of laying hen behaviour depending on the breed. Asian Austral. J. Anim. 2019a, 32, 1062-1068. [CrossRef] [PubMed]

4. Garnham, L.; Løvlie, H. Sophisticated fowl: The complex behaviour and cognitive skills of chickens and red junglefowl. Behav. Sci. 2018, 8, 13. [CrossRef]

5. Kozak, A.; Rozempolska-Rucińska, I.; Kasperek, K.; Bownik, A. Level of stress in relation to emotional reactivity of hens. Ital. J. Anim. Sci. 2019b, 18, 1252-1258. [CrossRef]

6. Rozempolska-Rucińska, I.; Zięba, G.; Kibała, L.; Próchniak, T.; Łukaszewicz, M. Genetic correlations between behavioural responses and performance traits in laying hens. Asian Austral. J. Anim. 2017a, 30, 1674. [CrossRef]

7. Rozempolska-Rucinska, I.; Kibala, L.; Prochniak, T.; Zieba, G.; Lukaszewicz, M. Genetics of the Novel Object Test outcome in laying hens. Appl. Anim. Behav. Sci. 2017b, 193, 73-76. [CrossRef]

8. Janczak, A.M.; Heikkilä, M.; Valros, A.; Torjesen, P.; Andersen, I.L.; Bakken, M. Effects of embryonic corticosterone exposure and post-hatch handling on tonic immobility and willingness to compete in chicks. Appl. Anim. Behav. Sci. 2007, 107, 275-286. [CrossRef]

9. Lindqvist, C.; Janczak, A.M.; Natt, D.; Baranowska, I.; Lindqvist, N.; Wichman, A.; Lundeberg, J.; Lindberg, J.; Torjesen, P.A.; Jensen, P. Transmission of stress-induced learning impairment and associated brain gene expression from parents to offspring in chickens. PLoS ONE 2007, 2, 364. [CrossRef]

10. Lay, D.C., Jr.; Fulton, R.M.; Hester, P.Y.; Karcher, D.M.; Kjaer, J.B.; Mench, J.A.; Mullens, B.A.; Newberry, R.C.; Nicol, C.J.; O'Sullivan, N.P.; et al. Hen welfare in different housing systems. Poult. Sci. 2011, 90, $278-294$. [CrossRef]

11. Brunberg, E.I.; Grova, L.; Serikstad, G.L. Genetics and welfare in organic poultry production: A discussion on the suitability of available breeds and hybrids. In Bioforsk Report; Bioforsk: Tingvoll, Norway, 2014; Volume 9 , pp. 1-28.

12. Sorato, E.; Zidar, J.; Garnham, L.; Wilson, A.; Løvlie, H. Heritabilities and co-variation among cognitive traits in red junglefowl. Philos. T. R. Soc. B Biol. Sci. 2018, 373, 20170285. [CrossRef] [PubMed]

13. van der Eijk, J.A.; Lammers, A.; Li, P.; Kjaer, J.B.; Rodenburg, T.B. Feather pecking genotype and phenotype affect behavioural responses of laying hens. Appl. Anim. Behav. Sci. 2018, 205, 141-150. [CrossRef]

14. Piepho, H.P.; Lutz, V.; Kjaer, J.B.; Grashorn, M.; Bennewitz, J.; Bessei, W. The presence of extreme feather peckers in groups of laying hens. Animal 2017, 11, 500-506. [CrossRef] [PubMed]

15. Della Costa, N.S.; Navarro, J.L.; Bernad, L.; Marin, R.H.; Martella, M.B. Effect of maternal environment on yolk immunoreactive corticosterone and its influence on adrenocortical and behavioral activity in chicks of Greater Rhea (Rhea americana). Horm. Behav. 2019, 114, 104534. [CrossRef] [PubMed]

16. Henriksen, R.; Rettenbacher, S.; Groothuis, T.G. Maternal corticosterone elevation during egg formation in chickens (Gallus gallus domesticus) influences offspring traits, partly via prenatal undernutrition. Gen. Comp. Endocr. 2013, 191, 83-91. [CrossRef]

17. Navara, K.J.; Pinson, S.E. Yolk and albumen corticosterone concentrations in eggs laid by white versus brown caged laying hens. Poult. Sci. 2010, 89, 1509-1513. [CrossRef]

18. Nordgreen, J.; Janczak, A.M.; Bakken, M. Effects of prenatal exposure to corticosterone on filial imprinting in the domestic chick, Gallus gallus domesticus. Anim Behav 2006, 72, 1217-1228. [CrossRef]

19. Freire, R.; van Dort, S.; Rogers, L.J. Pre-and post-hatching effects of corticosterone treatment on behavior of the domestic chick. Horm Behav 2006, 49, 157-165. [CrossRef]

20. Inglis, I.R. The Central Role of Uncertainty Reduction in Determining Behaviour. Behav 2002, 137, 1567-1599. [CrossRef] 
21. Panksepp, J. Affective consciousness: Core emotional feelings in animals and humans. Conscious Cogn 2005, 14, 30-80. [CrossRef]

22. Witkowski, A.; Kasperczyk, K.; Sławinska, A.; Bednarczyk, M. The breed of the month: Green-legged Partridgelike. An old native Polish hen. GlobalDiv Newsletter 2009, 9, 12-5.

23. Branciari, R.; Mugnai, C.; Mammoli, R.; Miraglia, D.; Ranucci, D.; Dal Bosco, A.; Castellini, C. Effect of genotype and rearing system on chicken behavior and muscle fiber characteristics. J. Anim. Sci. 2009, 87, 4109-4117. [CrossRef] [PubMed]

24. Flock, D.K.; Norman, L. Criteria for the competitiveness of different management systems and strain differences in the adaptability of layer hens to non-cage environments. In Proceedings of the 16th Baltic and Finnish Poultry Conference, Vantaa, Finland, 3 October 2008; World's Poultry Science Association: Finland Branch, Jokioinen, Finland, 2008.

25. Novkovic, T.; Mittmann, T.; Manahan-Vaughan, D. BDNF contributes to the facilitation of hippocampal synaptic plasticity and learning enabled by environmental enrichment. Hippocampus 2015, 25, 1-15. [CrossRef] [PubMed]

26. Uitdehaag, K.A.; Rodenburg, T.B.; Van Reenen, C.G.; Koopmanschap, R.E.; De Vries Reilingh, G.D.; Engel, B.; Buist, W.G.; Komen, H.; Bolhuis, J.E. Effects of genetic origin and social environment on behavioral response to manual restraint and monoamine functioning in laying hens. Poult. Sci. 2011, 90, 1629-1636. [CrossRef]

27. De Haas, E.N.; Kemp, B.; Bolhuis, J.E.; Groothuis, T.; Rodenburg, T.B. Fear, stress, and feather pecking in commercial white and brown laying hen parent-stock flocks and their relationships with production parameters. Poult. Sci. 2013, 92, 2259-2269. [CrossRef]

28. Fraisse, F.; Cockrem, J.F. Corticosterone and fear behaviour in white and brown caged laying hens. British Poult. Sci. 2006, 47, 110-119. [CrossRef]

29. Ericsson, M.; Jensen, P. Domestication and ontogeny effects on the stress response in young chickens (Gallus gallus). Sci. Rep. 2016, 6, 35818. [CrossRef]

30. Siwek, M.; Wragg, D.; Sławińska, A.; Malek, M.; Hanotte, O.; Mwacharo, J.M. Insights into the genetic history of Green-legged Partridge like fowl: Mt DNA and genome-wide SNP analysis. Anim. Gen. 2013, 44, 522-532. [CrossRef]

31. Campler, M.; Jöngren, M.; Jensen, P. Fearfulness in red junglefowl and domesticated White Leghorn chickens. Behav. Process. 2009, 81,39-43. [CrossRef]

32. Ericsson, M.; Fallahsharoudi, A.; Bergquist, J.; Kushnir, M.M.; Jensen, P. Domestication effects on behavioural and hormonal responses to acute stress in chickens. Physiol. Behav. 2014, 133, 161-169. [CrossRef] 